\title{
New Disease Reports \\ First report of Alternaria alstroemeriae on Alstroemeria sp. in Colombia
}

I. Valdés, J. Rodríguez, A. Portela and P. Jiménez*

Laboratorio de Fitopatologia, Universidad Militar Nueva Granada. Carrera 11 \#101-80 Bogota, Colombia

*E-mail: pedro.jimenez@unimilitar.edu.co

Received: 06 Feb 2014. Published: 18 May 2014. Keywords: Black spot

Alstroemeria (Alstroemeria sp.) is an ornamental plant native to South America, which has become important to the Colombian cut flower industry with exports reaching more than US\$43 million in 2013 (ASOCOLFLORES, 2013). Alstroemeria is mainly cultivated in the Antioquia and Cundinamarca departments of Colombia. In 2012, some growers reported the occurrence of a black spot disease on the leaves proximate to flowers in greenhouse facilities near Bogotá, Colombia, observing that 15 to $30 \%$ of plants were infected, thereby affecting the amount of marketable product. Field lesions were circular brown spots, surrounded by a chlorotic halo. The lesions later became irregular and necrotic (Fig. 1 A, B, D). Basipetal conidia chains were observed when infected tissues were incubated in humid chambers for two to three days (Fig1 C). Since conidia were characteristic of the genus Alternaria, and symptoms were similar to those described by Yamagishi et al. (2009), studies were conducted to identify the causal agent.

For the isolation and morphological identification of the fungus, portions of infected tissue were surfaced-sterilised with $0.5 \% \mathrm{NaOCl}$ for two minutes and washed twice with sterile water. The tissue was placed on potato dextrose agar (PDA) for one week in the dark at $25^{\circ} \mathrm{C}$. Several single spore cultures were recovered and subcultured on potato carrot agar (PCA). After three to four days at $25^{\circ} \mathrm{C}$, sporulation pattern and conidia size were recorded and analysed with ImageJ software (Shneider et al., 2012). Conidia $(\mathrm{n}=400)$ produced on PCA were $29.8 \pm 6.6 \mu \mathrm{m}$ long by $10.7 \pm 1.2$ $\mu \mathrm{m}$ wide (length/width ratio $=2.82$ ). Presence of submerged hyphae on the PCA (Fig. 3) was consistent with the description of Alternaria alstroemeriae (Simmons, 2007) A culture of the isolate was deposited in Universidad de Los Andes mycological collection, in Bogotá, Colombia, under the number ANDES-F 1042.

Conidia, produced after eight days culture on PCA, were harvested by flooding the cultures with $5 \mathrm{ml}$ of sterile distilled water (SDW), and dislodging the conidia with a glass bent rod, this procedure being repeated three times. They were then inoculated on detached leaves and on whole plants of alstroemeria. The inoculum concentration was adjusted to $1.45 \mathrm{x}$ $10^{6}$ conidia/ml in an aqueous solution of microbiological grade gelatin (1\% w/v). Evaluation of pathogenicity on detached leaves was accomplished by spraying the conidial suspension on leaves placed in small flasks containing a sucrose solution $(5 \mathrm{~g} / \mathrm{l})$ to prevent tissue wilting. Two control groups were established, leaves in one of them were sprayed with the gelatin aqueous solution, and the leaves in the other group were sprayed with SDW. Evaluation on whole plants was performed on 16-week-old plants using the prepared conidial suspension, and kept under greenhouse conditions $\left(18^{\circ} \mathrm{C}\right.$ and $80 \%$ RH). Symptoms on detached leaves and whole plants were evident three days after inoculation, while both controls remained symptomless. $A$. alstroemeriae was re-isolated from lesions fulfilling Koch's postulates (Fig. 2).

To the best of our knowledge, A. alstroemeriae has been reported on alstroemeria only in Japan (Yamagishi et al., 2009). This is the first report of this pathogen causing disease on Alstroemeria sp. in Colombia and South America. We consider this report as a contribution to the overall knowledge of diseases occurring on ornamentals in Colombia. Since the cut flower industry is an important export activity in Colombia, better understanding of its diseases is relevant in order to establish disease control strategies.

\section{Acknowledgements}

This research was supported by Vicerrectoría de Investigaciones at Universidad Militar Nueva Granada (Project CIAS-840).

\section{References}

ASOCOLFLORES (Colombian Association of Flower Producers), 2013. Estadísticas Exportaciones Enero Septiembre 2013.

http://www.asocolflores.org/

Schneider CA, Rasband WS, Eliceiri KW, 2012. NIH Image to ImageJ: 25 years of image analysis. Nature Methods 9, 671-675. http://dx.doi.org/10.1038/nmeth.2089

Simmons EG, 2007. Alternaria, an identification manual. CBS Biodiversity series 6, 444-445. Netherlands: CBS

Yamagishi N, Nishikawa J, Oshima Y, Eguchi N, 2009. Black spot disease of alstroemeria caused by Alternaria alstroemeriae in Japan. Journal of General Plant Pathology 45, 401-403.

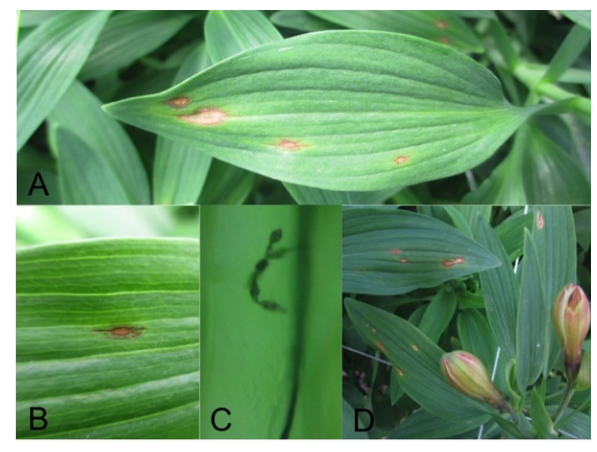

Figure 1

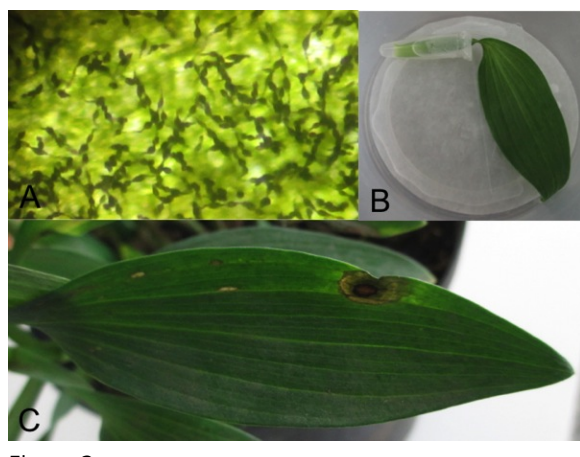

Figure 2
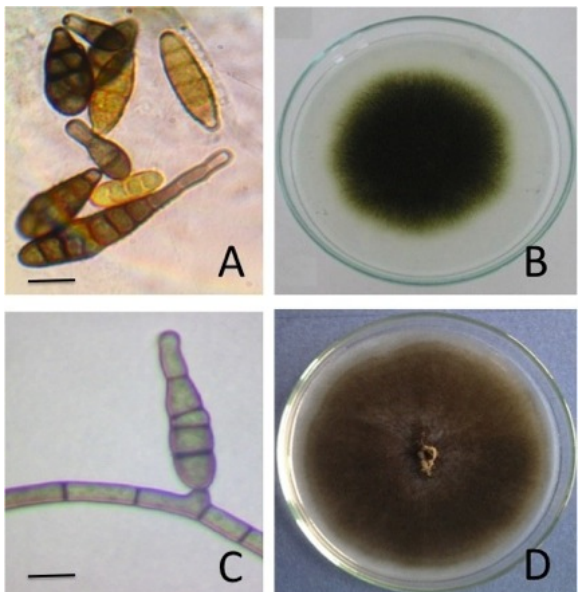

Figure 3

To cite this report: Valdés I, Rodríguez J, Portela A, Jiménez P, 2014. First report of Alternaria alstroemeriae on Alstroemeria sp. in Colombia. New Disease Reports 29, 21. http://dx.doi.org/10.5197/j.2044-0588.2014.029.021

(C) 2014 The Authors

This report was published on-line at www.ndrs.org.uk where high quality versions of the figures can be found. 